\title{
Commentary: Obamacare and American National Identity
}

\section{Raywat DEONANDAN* 1}

1 Professor, University of Ottawa, Canada

*Auteur(e) correspondant | Corresponding author: raywat.deonandan@uottawa.ca

On March 23, 2010, US President Barack Obama signed into law the Patient Protection and Affordable Care Act (PPACA) (United States of America, 2010), commonly called "Obamacare." Representing the most significant revision of the American health care system in over four decades, PPACA is aimed primarily at decreasing the number of uninsured Americans and reducing the overall out-of-pocket costs of individual health care.

The Act has been characterized by its opponents as an American version of socialized medicine (Faria, 2012). Generally defined as a system of medical care that is publicly financed and government administered, socialized medicine manifests in a variety of forms around the world. American experiences with it include the Veterans Health Administration, the military health care system, and the Indian Health Service, to the extent that these services are government-administered care, albeit reserved for a specialized demographic in each case (Boffey, 2007). In addition, Medicare and Medicaid are forms of publicly funded health services, though the individual shares some degree of cost.

In a sense, the adoption of PPACA constitutes a national paradigm shift in American culture. Long selfcharacterized as a society of rugged individualists, the USA has put forth a public face of risk-taking and the acceptance of individual responsibility for individual lifestyle choices, however unhealthy those choices might be. Described by some as a mythic identity, the extent to which this characterization is seated in reality is open to debate (McDonald, 2010). But its prevalence in American media, art, and expressions of nationalism suggest a strong vein of symbolic individualism that percolates through Americans' values and self-perception (Harms, 2007). It is therefore not surprising that the opposition to PPACA came from Republicans, whose public values espoused extreme versions of the individualistic motif, including a minimal governmental role in public life, looser firearm regulations, and greater freedom from statedirected education.
With the advent of PPACA, it will be interesting to see the extent to which American self-identification with individualistic values may diminish. In a society with socialized medicine, it quickly becomes apparent that individual actions have a direct impact on the wherewithal of the group, usually through finances. If population health costs, as reflected through either taxation or individual co -payments, are responsive to the perturbations of individual extremes, then a minority's decision to engage in risky behaviours may affect the affordability of health care for the greater population.

Some of the more obvious examples of where this conflict in values may arise include attitudes around smoking and helmet wearing. Presently, laws requiring all motorcycle riders to wear helmets are in place in 19 states and the District of Columbia, while 28 states require some motorcyclists to wear helmets; and three states (Illinois, Iowa, and New Hampshire) have no helmet laws whatsoever (Insurance Institute for Highway Safety, 2013). If, in those latter states in particular, serious head accidents related to a failure to use helmets results in a measurable financial burden on the new public health insurance plan, it will be interesting to note whether political and social pressure will be applied to legislators to enact strict helmet laws.

Currently, nine states have bans on smoking in restaurants, bars, or non-hospitality workplaces (Wikipedia, 2013). Arguments for restricting public smoking range from comfort to individual health to public health. Under PPACA and the possibility that public health may be perceived to migrate from a state responsibility to a public responsibility, there may evolve a greater push to enact public smoking bans under the banner of cost control, as lessened exposure to tobacco products may minimize claims on the public health insurance system. It is commonly noted that the overall economic costs to the US economy are over $\$ 50$ billion annually (Morreale, 1998). However, health costs are actually lower, since smokers have shortened lifespans (Morreale, 1998). That 
may change if PPACA allows previously unaffordable extreme and costly end-of-life measures to be attempted on this population.

As Canadians have long noted, systematized health care can be intimately associated with national identity. The potential exists for "Obamacare" to contribute to the dynamic definition of American national identity, veering from its frontiersman iconography toward something more akin to a web of social responsibilities.

\section{References}

Boffey, P. (2007, September 28). The socialists are coming! The socialists are coming!. The New York Times. Retrieved from http://www.nytimes.com/2007/09/28/

opinion/28fri4.html?_r=o

Faria, M. A. (2012). ObamaCare: Another step toward corporate socialized medicine in the US. Surgical Neurology International, 3(71). doi: 10.4103/2152-7806.97729

Harms, W. (2007). America's individualist culture influences the ability to view others' perspectives. The University of Chicago Chronicle, 26(19). Retrieved from http:// chronicle.uchicago.edu/070712/perspectives.shtml

Insurance Institute for Highway Safety. Motorcyle and bicycle helmet use laws. Jan, 2013. Retrieved from http:// www.iihs.org

McDonald, J. (2010). Interplay: Communication, Memory, and Media in the United States. Goettingen: Cuvillier.

ISBN 3-86955-322-7.

Morreale M. (1998). Fact Sheet: Risk Behaviour and Health Care Utilization. Nursing Effectiveness, Utilization and Outcomes Research Unit. McMaster University and University of Toronto. Retrieved from http://bit.ly/ X3ojFN

United States of America. (2010). 111th Congress, Public Law 111-148. (2010). The patient protection and affordable care act (HR 3590). Retrieved from http:// www.gpo.gov/fdsys/pkg/PLAW-111publ148/html/PLAW111publ148.htm

Wikipedia. (2013). List of smoking bans in the United States. Retrieved from http://en.wikipedia.org/wiki/ List_of_smoking_bans_in_the_United_States 